\title{
Respiratory health in a total very low birthweight cohort and their classroom controls
}

\begin{abstract}
Alice McLeod, Patricia Ross, Sheena Mitchell, Dorothy Tay, Leslie Hunter, Alastair Hall, James Paton, Lesley Mutch
\end{abstract}

\begin{abstract}
Aims-To compare the respiratory health and function at 8 to 9 years of age of a total population based cohort of 300 very low birthweight (VLBW) children with that of two classroom controls $(n=590)$ matched for age and sex.

Study design-Cohort study with controls. Setting-Schools throughout Scotland.

Results-The VLBW children were more likely than their peers to use an inhaler, to be absent from school, and to be admitted to hospital because of respiratory illness. They were significantly shorter than their classroom controls, but even after adjusting for differences in height, the VLBW children had reduced forced vital capacity (FVC); this was associated with a history of prolonged ventilation ( $>28$ days) and pneumothorax in the neonatal period. There were no significant differences between the groups in forced expiratory volume in one second $\left(\mathrm{FEV}_{1}\right)$ /FVC but twice as many $(7.9 \% v 3 \cdot 7 \%)$ of the VLBW children had ratios $<70 \%$, denoting obstructive airways disease. Poor expiratory function was associated with neonatal respiratory distress syndrome, prolonged ventilation, and the need for $>40 \%$ oxygen. Exercise induced airway narrowing was increased in VLBW children (odds ratio $=2 \cdot 0 ; 95 \%$ confidence interval $1 \cdot 2$ to 3.4) and was very little changed by adjustment for inhaler use and exposure to cigarette smoke.

Conclusions-As in other low birthweight cohorts, respiratory morbidity was increased. Unlike previous studies, FVC was more affected than expiratory function in this VLBW population. Our findings support the hypothesis that poorer lung function is associated with very low birth weight, but not with intrauterine growth retardation.

(Arch Dis Child 1996; 74: 188-194)
\end{abstract}

Keywords: lung function, respiratory morbidity, very low birth weight.

Health

J Paton

Correspondence to: Alice McLeod, Public Health Research Unit, University of Glasgow, 1 Lilybank Gardens, Glasgow G12 8RZ.

Accepted 30 October 1995
Low birth weight has been implicated in the genesis of later respiratory morbidity in populations born some $40-50$ years ago. Barker et al in particular have suggested that poor lung function and death from chronic obstructive airways disease in adult life was associated with lower birth weight and weight at 1 year via the mechanism of poor lung growth. ${ }^{1}$ Follow up studies of the increasing numbers of low birthweight infants now surviving provide an opportunity to investigate the association between birth weight and respiratory health in more recent cohorts.

Previous neonatal follow up studies have shown that the children who were at increased risk of respiratory morbidity were those who had respiratory support in the neonatal period. ${ }^{2}{ }^{3}$ Chan et al, however, found that low birthweight infants, irrespective of whether they had required ventilation in the neonatal period, had poorer respiratory function at 7 years than their classroom peers. ${ }^{45}$ Others have shown that the increased hospital admission rates seen in very low birthweight (VLBW) populations compared with heavier children are associated mainly with admission for both upper and lower respiratory tract infections. ${ }^{6-9}$ Chan et al reported that their low birthweight children (defined as those $<2000$ g) were of similar height to their peers by the age of 7 years and had similar forced vital capacity (FVC), but reduced forced expiratory volume in one second $\left(\mathrm{FEV}_{1}\right)$; this effect was worse for boys and where there was a history of maternal smoking. ${ }^{4}$ In a large study of schoolchildren throughout the UK, Rona and his colleagues reported that birth weight for gestational age (that is, intrauterine growth) was significantly associated with FVC and $\mathrm{FEV}_{1}$ after taking gestational age, parental smoking, and social factors into account. ${ }^{10}$ In a large study of army recruits from Israel, Seidman et al found a significantly increased risk of asthma (after adjusting for ethnic origin, social class, paternal education, maternal age, and birth order) among those whose birth weight was below $2500 \mathrm{~g} .{ }^{11}$

In contrast, Kitchen et al reported that in their very low birthweight population (born between 1977 and 1982) there was little evidence of impaired lung function at 8 years. ${ }^{12}$ Changes in the management of neonatal respiratory disease over the past 10 years may be associated with these improvements in later lung function and the experience of an even more recent cohort is presented here. 
The Scottish low birthweight study is a population based study of all infants liveborn in Scotland in 1984 who had birth weights less than $1750 \mathrm{~g} .{ }^{13}$ Those survivors who had birth weights less than $1500 \mathrm{~g}$ were reviewed at 8 to 9 years in school. This review provided the opportunity to investigate the respiratory function of a more recent cohort of VLBW children, to compare their performance with that of heavier birthweight children who lived in the same localities, and to test hypotheses about the relationship of low birth weight and intrauterine growth retardation to later lung function.

We knew that our cohort, unlike that of Chan et al, had been significantly shorter than reference populations at the age of 4.5 years. ${ }^{13}$ We therefore expected to find that, compared with controls, the VLBW children would have smaller lungs and increased bronchial reactivity.

\section{Methods}

All 908 liveborn children born in Scotland in 1984 , weighing less than $1750 \mathrm{~g}$ at birth, were eligible for entry into the study; of these 896 $(99 \%)$ were enrolled. Maternal and perinatal data were collected by a research midwife and the children have been followed up at intervals since. At 8-9 years, a review was planned of those 341 children, weighing less than $1500 \mathrm{~g}$ who were still resident in Scotland. Their performance on a number of measures of growth, cognitive and neuromotor performance, ${ }^{14}$ blood pressure, and respiratory function was compared with that of two classroom peers of the same sex, who were nearest in date of birth to the index child.

\section{DATA COLLECTION}

Permission for the study was given by the ethics committees of all health boards in Scotland and the directors of education in every region in Scotland. With the written permission of head teachers and parents, the children's respiratory function was assessed in school by four nurses trained in the study techniques.

\section{MEASUREMENT OF GROWTH AND LUNG \\ FUNCTION}

The nurses were trained by an auxologist to measure height and weight using standard techniques recommended by the Child Growth Foundation. ${ }^{15}$ After training by a respiratory technician, the nurses carried out tests of respiratory function, using a computerised pneumotachograph system (Compact, Vitalograph Ltd). FVC and FEV 1 were measured on three occasions; at baseline, and again at five and 10 minutes after five minutes of running exercise according to the protocol of Strachan. ${ }^{16}$ The period of exercise took place in most settings within a school corridor or gymnasium, but on a few occasions had to be done outside because of pressure of space. Each measurement recorded was the best of three attempts (based on the greatest sum of FVC and $\mathrm{FEV}_{1}$ ) achieved by the child, wearing a nose clip. The mean (SD) ambient temperature recorded at the time of lung function measurement was $21.0(2.2)^{\circ} \mathrm{C}$ (minimum $15 \cdot 0^{\circ} \mathrm{C}$ ). Recordings were made at a later date if the child had had bronchodilators within the previous six hours.

Information about previous hospital admissions was obtained from parental questionnaire. Parents were also asked whether the child suffered from frequent coughs and colds, or had colds which required treatment from the general practitioner, or caused the child to be absent from school. In addition to this, parents were asked to report whether their child wheezed, whether this was with or without a cold, or after exercise, and whether there was a family history of asthma, bronchitis, or allergies. Parental questionnaires also supplied information on housing, including the presence of mould or dampness, as well as details of the child's exposure to tobacco smoke. No independent information on a formal diagnosis of asthma was available and so the use of an inhaler was taken as an indicator of doctor diagnosed asthma.

Perinatal data, abstracted from maternal and infant case records were available for the VLBW children. Four markers of respiratory health in the perinatal period were investigated for their association with lung function at 8-9 years; duration of artificial ventilation, duration of oxygen at levels more than $40 \%$, the presence of the respiratory distress syndrome, and pneumothorax.

\section{STATISTICAL ANALYSIS}

For the majority of children, three measures of FVC and FEV 1 were available. The measures of $\mathrm{FEV}_{1}$ depended on the relation to exercise in the protocol. Given practice in the procedure, FVC is unaffected by exercise and should remain constant and therefore, the maximum FVC recorded for each child was used to compare the two study groups.

Recently published British standards were used initially to obtain spirometric SD scores, corrected for height and sex, in order to compare the study groups. ${ }^{17}$ The Scottish control children, however, had a larger FVC, on average, than the population used as standard. There was also evidence of a sex bias with the shift from the norms being more pronounced for our control girls (mean (SD) FVC SD score for boys was $0.24(1.62)$ and for girls $0.44(1 \cdot 44))$. The results for the VLBW children were therefore considered, more appropriately, relative to their classroom peers.

The relationship between height and FVC is known to have non-constant variance, ${ }^{18}$ with increasing variability of FVC with increasing height, and this was present in our results. To remove the heteroscedasticity, natural logarithm (ln) transformations were made on both variables. These transformations had a negligible effect on the normality of the data. FVC was compared by an analysis of covariance, regressing $\ln$ (FVC) on $\ln$ (height) and adjusting 
Table 1 Prevalence of factors associated with respiratory morbidity; values are number (\%)

\begin{tabular}{lrr}
\hline & $\begin{array}{c}V L B W \\
(n=241)\end{array}$ & $\begin{array}{c}\text { Control } \\
(n=508)\end{array}$ \\
\hline $\begin{array}{l}\text { Family history } \\
\text { Bronchitis }\end{array}$ & $46(19)$ & $97(19)$ \\
Wheezing & $42(18)$ & $90(18)$ \\
Allergies & $62(26)$ & $132(26)$ \\
Housing & & $70(14)$ \\
Dampness & $27(11)$ & $53(11)$ \\
Mould & $20(8)$ & \\
Exposure to smoking (cigarettes/day) & $321(65)$ \\
Mother & $124(53)$ & $87(18)$ \\
0 & $39(17)$ & $89(18)$ \\
$1-19$ & $73(31)$ & $248(49)$ \\
$20+$ & $88(37)$ & $71(14)$ \\
All adults & $31(13)$ & $186(37)$ \\
0 & $119(50)$ & \\
$1-19$ & & \\
$20+$ & &
\end{tabular}

for sex and case status to estimate the difference between VLBW and control children. Adjusted means were obtained from the model to remove the effect of height, and their confidence intervals (CIs) were calculated on the natural logarithm scale and transformed to obtain values for FVC in litres. Other important factors (age, current weight, social class, and exposure to tobacco smoke) were also explored in this model to establish their association with FVC and their effect on the difference between study groups.

$\mathrm{FEV}_{1}$ is dependent on FVC, a factor found to differentiate the study groups. In order to compare VLBW and control children in respect of expiratory function, baseline $\mathrm{FEV}_{1} / \mathrm{FVC}$ ratios were calculated. As the distribution of $\mathrm{FEV}_{1} / \mathrm{FVC}$ was not normal, with the ratios being upwardly skewed toward unity, the non-parametric Wilcoxon rank sum test was used to compare $\mathrm{FEV}_{1} / \mathrm{FVC}$ distributions. Ratios categorised by control centiles, were also used to investigate the difference between the two study populations in respect of airways obstruction. The prevalence of exercise induced airways narrowing (EIAN) was assessed by the number of children experiencing a $10 \%$ or more fall in $\mathrm{FEV}_{1}$ after five minutes of free range running. The risk of EIAN in the VLBW population compared with the controls was estimated by the odds ratio (OR) with approximate $\mathrm{CI}$ and adjusted for confounding variables using logistic regression. ${ }^{19}$ Proportions were compared by a $\chi^{2}$ test of association and the risk of respiratory morbidity was again estimated by ORs with approximate CIs.

The methods used to compare cases and controls in respect of spirometric measures were also employed to test the associations between

Table 2 Prevalence and risk of respiratory morbidity in the VLBW population

\begin{tabular}{lllll}
\hline & $\begin{array}{l}\text { No (\%) VLBW } \\
(n=241)\end{array}$ & $\begin{array}{l}\text { No (\%) control } \\
(n=508)\end{array}$ & OR & $95 \% C I$ \\
\hline Wheeze & & & & \\
$\quad$ Alone & $22(9)$ & $23(5)$ & $2 \cdot 1$ & 1.2 to 3.9 \\
$\quad$ With cold & $56(23)$ & $67(13)$ & 2.0 & 1.3 to 3.0 \\
$\quad$ After exercise & $28(12)$ & $32(6)$ & $2 \cdot 0$ & 1.2 to 3.3 \\
Frequent coughs and colds & $55(23)$ & $52(10)$ & 2.6 & 1.7 to 3.9 \\
Visited GP for coughs and colds & $67(28)$ & $80(16)$ & 2.1 & 1.4 to 3.0 \\
School absences for chest problems & $31(13)$ & $24(5)$ & 3.0 & 1.7 to 5.2 \\
Respiratory hospital admissions & $40(17)$ & $23(5)$ & 4.3 & 2.5 to 7.4 \\
Inhaler & $40(13)$ & $45(8)$ & 1.9 & 1.2 to 2.9
\end{tabular}

^Information from nurses' assessment, hence all children, excluding one VLBW child, responded. $\mathrm{GP}=$ general practitioner. perinatal factors and lung function in the VLBW population at 8-9 years. Duration of both artificial ventilation and the use of oxygen at levels more than $40 \%$ were not normally distributed and were therefore categorised as none, $1-6$ days, $7-27$ days, and $\geqslant 28$ days in order to test for any dose-response relationship.

\section{Results}

Of the 341 VLBW children eligible for inclusion in this phase of the follow up, $324(96 \%)$ were assessed at 8-9 years. Two children had been adopted and we were asked not to contact them, 11 parents refused further review, and four could not be traced. Only those children in mainstream education were included in the current analysis of respiratory function. This was due to the lack of appropriate controls for the 24 VLBW children in special schools and the fact that those children were unable to undertake the tests for reasons connected with their disabilities. Of the $300 \mathrm{VLBW}$ and 590 control children assessed by the nurses, 292 and 574, respectively, provided at least the baseline measurement of FVC. All these children, except two VLBW cases, were also able to provide at least a baseline measurement of $\mathrm{FEV}_{1}$. Reasons for missing data in this part of the study were largely due to equipment failure.

The mean age for both VLBW and control children was $8 \cdot 8$ years (case $\mathrm{SD}=0 \cdot 3$; control $\mathrm{SD}=0.4)$. The numbers of girls in each group were $153(51 \%)$ and $298(51 \%)$, respectively. The two groups of children differed greatly in height, with the control children closely resembling the distribution of the Child Growth Foundation's 1993 norms, while 14\% $(n=42)$ of the VLBW population had a height below the third centile for age and sex, and $76 \%(n=227)$ were below the 50th centile. Mean (SD) heights for cases and controls were $127 \cdot 9 \mathrm{~cm}(6 \cdot 0)$ and $131 \cdot 4(6 \cdot 0)$ respectively.

Parental questionnaires were received, after a second mailing, from $241(80 \%)$ VLBW and $508(86 \%)$ control children, a significantly better response rate from the latter.

\section{RESPIRATORY MORBIDITY AND ASSOCIATED} FACTORS

Table 1 shows the proportions of children in each study group who were exposed to environmental factors associated with respiratory morbidity and who had a family history of respiratory disorders. The VLBW population did not differ significantly from the control children in respect of family history of bronchitis, wheezing or allergies, or in the presence of dampness or mould in the home. Current exposure to smoking was significantly more common in the VLBW children, both for exposure from the mother and additive exposure from all adults living with the child.

The VLBW population was found to have an increased risk of wheezing, both with and without a cold or after exercise. They also had more frequent coughs and colds (>5/year), and they were more likely to see their general practitioner because of this (table 2). They were more often 


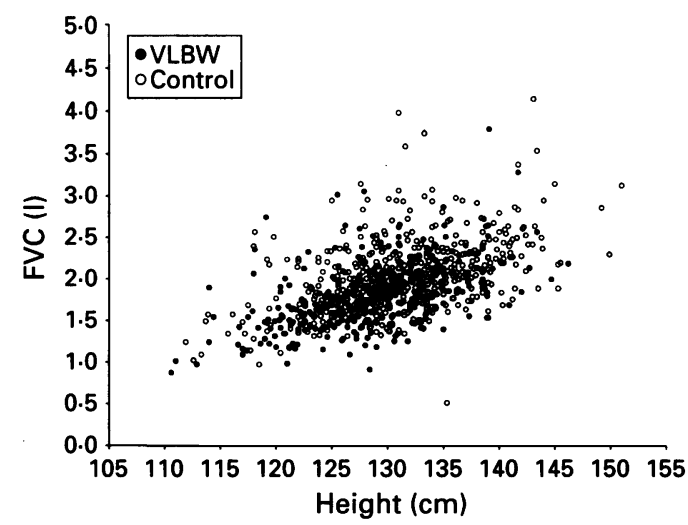

Figure 1 Association between FVC and height.

absent from school because of respiratory symptoms and were four times more likely to have been admitted to hospital on at least one occasion for respiratory problems (OR $4 \cdot 3 ; 95 \% \mathrm{CI}$ 2.5 to $7 \cdot 4$ ). Inhaler use was reported significantly more often in the VLBW population (13\% v 8\%: OR $1 \cdot 9$; $95 \%$ CI $1 \cdot 2$ to $2 \cdot 9)$.

\section{FORCED VITAL CAPACITY}

As FVC depends strongly on height, and because the height of our VLBW population differed greatly from that of the controls, height was an important confounding variable. Figure 1 shows the maximum FVC plotted against height for both study groups; the 'fanning out' of the points with increasing values illustrates the non-constant variance characteristic of FVC. In fig 2 the mean FVC for height centile groups is plotted for each study group and illustrates a reduction at all heights for the VLBW population with the exception of those children with heights between the 50 th and 75 th centiles. An analysis of covariance, regressing $\ln (\mathrm{FVC})$ on $\ln$ (height) and correcting for sex, showed the FVC to be significantly reduced in the VLBW population $(p<0.001)$; the difference between the study groups was the same for boys and girls. The slope of the regression between $\ln$ (FVC) and ln(height) was not significantly different between the study groups. Adjusted FVC means $(95 \% \mathrm{CI})$, standardised to the mean height of the total study population $(130.1 \mathrm{~cm})$ were 1.81 litres $(1.76$ to 1.85$)$ for the VLBW children compared with 1.91 litres (1.89 to 1.95$)$ for their controls. Thus even

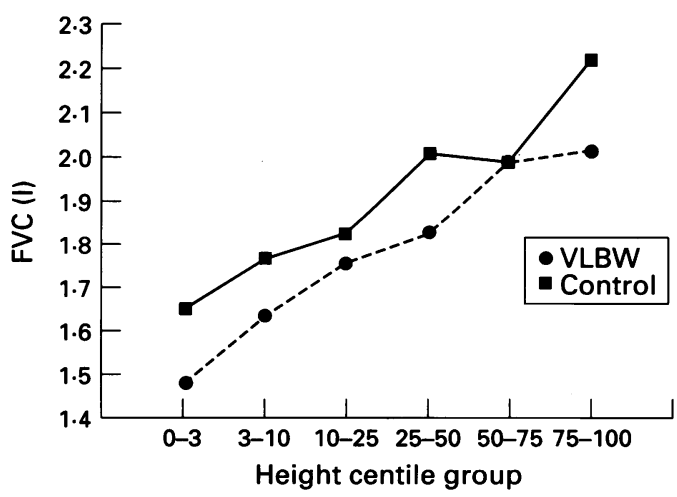

Figure 2 FVC by height centiles: VLBW children compared with controls. after adjusting for their height, the VLBW children had a smaller FVC than the control children. Weight, but not age, was significantly related to FVC after adjusting for height. The additional variance explained by weight was, however, small $(<1 \%)$ and had a negligible effect on the adjusted means. Social class, in four categories (I, II, and IIInm; IIIm; IV and $\mathrm{V}$; other and missing) was also not significantly associated with FVC, after adjusting for height.

The effect of exposure to cigarette smoke on FVC was investigated in two stages; the additive exposure from all adults living with the child and exposure from the mother only; both variables were categorised as smoking or non-smoking. Additive exposure from all adults was not significantly associated with FVC; however, exposure from the mother alone was $(p<0.05)$, although the effect was not as expected. In both study groups, the children exposed to maternal smoking had, on average, larger FVC than those not exposed, although these findings were not consistent with a dose-response relationship when the level of smoking was taken into account.

FORCED EXPIRATORY VOLUME IN ONE SECOND Because of the reduction in FVC in the VLBW population, their $\mathrm{FEV}_{1}$ measurements could not be compared with the controls without first adjusting for FVC. The distribution of $\mathrm{FEV}_{1} / \mathrm{FVC}$ ratios for VLBW and control children were both skewed towards one (fig 3) with median ratios (interquartile range) being $0.88(0.82-0.94)$ and $0.90 \quad(0.84-0.94)$, respectively. A Wilcoxon rank sum test showed no significant differences in the distributions between the study groups. Airways obstruction is, however, characterised by low $\mathrm{FEV}_{1} / \mathrm{FVC}$ ratios and in order to investigate this further, ratios were categorised into three groups, $<0.70,0.70-0.84$, and $0.85+$, corresponding respectively to below the 5 th, 5 th -25 th, and above the 25 th centile of the control population. A $\chi^{2}$ test of association found this lower part of the $\mathrm{FEV}_{1} / \mathrm{FVC}$ distribution to be significantly different between the study groups $(p<0.05)$; the proportion of VLBW children who had ratios below 0.70 was twice that of the controls $(\mathrm{n}=23 v 22 ; 7 \cdot 9 \% v 3 \cdot 7 \%)$. After stratifying by sex, however, only the VLBW boys were significantly different from their controls.

Exposure to maternal smoking appeared to be related to a reduced expiratory function within the control group only; median $\mathrm{FEV}_{1} / \mathrm{FVC}$ for control children, exposed and unexposed were respectively 0.88 and 0.91 , while the median ratio for the VLBW children remained at 0.88 regardless of their exposure to maternal smoking. Wilcoxon rank sum tests confirmed that maternal smoking was significantly associated with a reduced expiratory volume in the control children only $(p<0.01)$. Maternal smoking was not associated with evidence of obstructive airways disease (that is, $\mathrm{FEV}_{1} / \mathrm{FVC}$ ratio $<0 \cdot 70$ ) in either study group. 


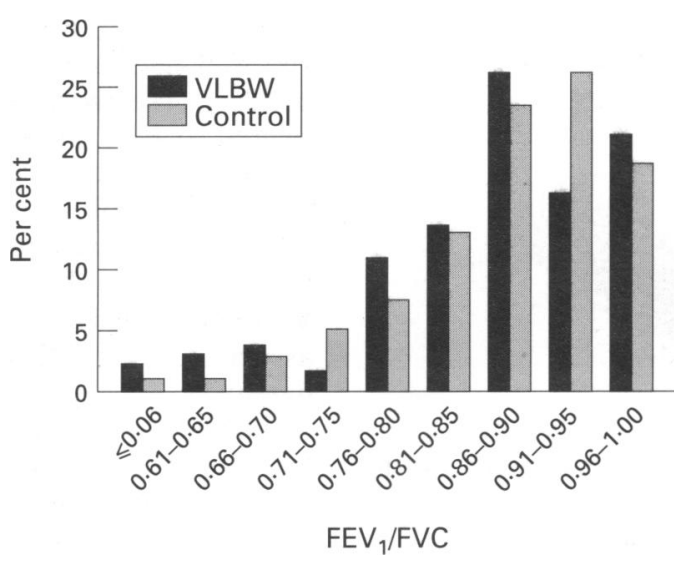

Figure $3 F E V_{1} / F V C$ ratio: VLBW children compared with controls.

EXERCISED INDUCED AIRWAYS NARROWING

A total of $30(10 \%)$ VLBW and $31(5 \%)$ control children experienced a $10 \%$ or more decrease in $\mathrm{FEV}_{1}$ after the exercise period, a significantly increased prevalence of EIAN in the VLBW population (OR=2.0;95\% CI $1 \cdot 2$ to $3 \cdot 4)$. EIAN has been shown to be increased in both children with asthma and in children exposed to maternal smoking, ${ }^{20}$ and our low birthweight population had comparatively more in both these risk categories (table 1). To correct for these factors, logistic regression was carried out adjusting for whether or not the child was currently using an inhaler and whether or not the child's mother smoked. Adjusting for inhaler use, which was significantly associated with EIAN, the odds ratio for the VLBW population became $1.9(95 \% \mathrm{CI}$ $1 \cdot 1$ to $3 \cdot 3)$. Adjusting for any smoking or heavy $(>20 /$ day) smoking resulted in a negligible increase in the odds ratio for the VLBW population. Maternal smoking was not significantly associated with EIAN for either VLBW or control children. The prevalence of EIAN was increased where parents reported that their child wheezed with a cold or after exercise:

PERINATAL FACTORS AND LUNG FUNCTION IN THE VLBW POPULATION

The four perinatal respiratory factors and their relationships to later lung function are sum-

Table 3 Perinatal factors and respiratory function in the VLBW cohort at 8-9 years

\begin{tabular}{|c|c|c|c|c|c|c|}
\hline & \multirow[b]{2}{*}{ No } & \multicolumn{2}{|l|}{$F V C$} & \multicolumn{2}{|c|}{$F E V_{1} / F V C$} & \multirow{2}{*}{$\begin{array}{l}\text { No (\%) } \\
\text { ELANt }\end{array}$} \\
\hline & & Mean $^{\star}$ & $95 \% C I$ & Median & No $(\%)<70 \% \dagger$ & \\
\hline \multicolumn{7}{|c|}{ Artificial ventilation (days) } \\
\hline None & 134 & 1.84 & 1.77 to 1.91 & 0.90 & $4(3)$ & $11(8)$ \\
\hline $1-6$ & 66 & 1.83 & 1.73 to 1.93 & 0.89 & 7 (11) & $7(11)$ \\
\hline $7-27$ & 57 & 1.83 & 1.73 to 1.94 & $0 \cdot 87$ & 7 (13) & $6(11)$ \\
\hline $28+$ & 34 & 1.65 & 1.52 to 1.78 & $0 \cdot 86$ & $5(15)$ & $6(18)$ \\
\hline \multicolumn{7}{|c|}{ Oxygen $\geqslant 40 \%$ (days) } \\
\hline None & 109 & $1 \cdot 81$ & 1.73 to 1.88 & $0 \cdot 89$ & $2(2)$ & $10(9)$ \\
\hline $1-6$ & 125 & 1.83 & 1.75 to 1.91 & 0.89 & $11(9)$ & $14(11)$ \\
\hline $7-27$ & 37 & 1.80 & 1.69 to 1.92 & $0 \cdot 86$ & $6(16)$ & $3(8)$ \\
\hline $28+$ & 21 & $1 \cdot 78$ & 1.61 to 1.97 & $0 \cdot 86$ & $4(20)$ & $3(15)$ \\
\hline \multicolumn{7}{|c|}{ Respiratory distress syndrome } \\
\hline No & 102 & $1 \cdot 81$ & 1.73 to 1.89 & 0.89 & $2(2)$ & $4(4)$ \\
\hline Yes & 190 & $1 \cdot 81$ & 1.75 to 1.88 & 0.88 & $21(11)$ & $26(14)$ \\
\hline \multicolumn{7}{|c|}{ Pneumothorax } \\
\hline & 272 & 1.83 & 1.78 to 1.89 & 0.89 & $21(8)$ & $28(10)$ \\
\hline Yes & 20 & 1.57 & 1.44 to 1.72 & $0 \cdot 88$ & $2(10)$ & $2(10)$ \\
\hline
\end{tabular}

*Adjusted for height and sex in analysis of covariance for VLBW cohort only, to a height of $130 \cdot 1 \mathrm{~cm}$. $+x^{2}$ test for association between $\mathrm{FEV}_{1} / \mathrm{FVC}<70 \%$ and EIAN with duration of artificial ventilation and oxygen $\geqslant 40 \%$ performed combining the middle categories of explanatory variables (none, $1-27$ days, and $28+$ days) because of small numbers. marised in table 3. Analysis of covariance showed that both prolonged artificial ventilation $(p<0.05)$ and the presence of pneumothorax $(\mathrm{p}<0.005)$ were significantly associated with a reduced FVC, with the decrease in FVC among children experiencing a pneumothorax remaining significant after adjustment for duration of ventilation. Only those children who were ventilated for 28 days or more had significantly reduced FVC compared with those who were not ventilated. Although birth weight and gestational age are inevitably related to the neonatal respiratory experience of the VLBW children, they were not themselves significantly related to FVC within the VLBW group. Poor expiratory function, defined as $\mathrm{FEV}_{1} / \mathrm{FVC}$ less than $70 \%$, was significantly associated with duration of artificial ventilation $(p<0.05)$, prolonged use of oxygen at levels of $40 \%$ or more $(p<0.005)$ as well as respiratory distress syndrome $(\mathrm{p}<0.01)$. Very few children without respiratory distress syndrome received artificial ventilation or prolonged oxygen; it was, therefore, not possible to establish the interdependence of the observed association between these perinatal factors.

The prevalence of EIAN was significantly increased in those children who had respiratory distress syndrome $(\mathrm{OR}=3.9 ; 95 \% \mathrm{CI} 1 \cdot 3$ to $11 \cdot 5$ ) but was not significantly associated with any of the other perinatal variables.

\section{Discussion}

In this study, we have described the respiratory health and function in a geographically based cohort of Scottish VLBW children born in 1984. Most studies of longer term function have related to heterogeneous populations cared for in tertiary referral centres with many infants being transferred in for care because of severe respiratory problems and their populations are therefore likely to be biased.

The most striking finding in the present study was that lung size as measured by FVC was reduced in the VLBW population. After adjustment for height, the mean reduction in FVC was $110 \mathrm{ml}$ in the VLBW infants. Moreover, expiratory function as measured by $\mathrm{FEV}_{1} / \mathrm{FVC}$ was relatively well maintained in the VLBW children and, on average, their $\mathrm{FEV}_{1} / \mathrm{FVC}$ was not reduced compared with the controls. The VLBW cohort did, however, have more children at the lower end of the distribution (fig 3), although the actual number in this category was small.

Our lung function findings are contrary to those of Chan et al where low birthweight children had maintained FVC and reduced $\mathrm{FEV}_{1}{ }^{4}$ The most likely explanations for the differences in our results are that our cohort were of lower birth weight and were population based. Kitchen $e t$ al 's study of VLBW children found little evidence of reduced respiratory function overall, although they did find that those children of extremely low birth weight (ELBW, <1000 g) had a reduced FVC compared with those with birth weights between $1000-1400$ g. ${ }^{12}$ We found no evi- 
dence of differential lung function for the ELBW children in the Scottish cohort. It may be noted, however, the Kitchen et al used published standards to obtain the percentage of predicted scores for lung function measures and our own experience of published norms was not favourable. Had we not included a control group in our study we would have reached different conclusions about the lung function of the VLBW cohort, highlighting the importance of control groups for epidemiological studies even when very recent norms are available.

As in earlier reports, ${ }^{512}$ we found that VLBW children had evidence of significant respiratory morbidity, particularly wheezing illnesses, compared with their classroom peers. Kitchen et al found increased levels of asthma and recurrent bronchitis which were associated with reduced flow rates. ${ }^{12}$ A number of studies have reported that respiratory symptoms are significantly associated with length of gestation, whereas lung function is related to birth weight. For example, Kelly et al stated that preterm birth per se, but not intrauterine growth retardation, predisposed to the later development of asthma. ${ }^{21}$ Rona et al found that every additional week of gestation reduced the risk of severe wheeze by about $10 \%$, independently of birth weight, while birth weight for gestation was significantly associated with lung function measures. ${ }^{10}$ Others, however, reporting on lung function in adolescents (born in 1975-7), reported that low birth weight at term (that is intrauterine growth retardation) was not associated with reduced lung function. ${ }^{22}$ Of the $300 \mathrm{VLBW}$ infants in our study, 94 (34\%) were also small for gestational age. These infants did not have either a reduced FVC or a poorer $\mathrm{FEV}_{1} / \mathrm{FVC}$ ratio than appropriately grown VLBW children. Thus, we also cannot confirm the association of obstructive airways disease with intrauterine growth retardation reported by Barker and colleagues. ${ }^{1}$ We acknowledge, however, that our study was not ideal to investigate such a hypothesis because the cohort was defined by birth weight and not also by gestational age.

Some of our findings in respect of exposure to smoking are unexpected but our intention in this paper was to focus on the effects of being very low birth weight on respiratory function rather than on known associations between smoking and respiratory function. In the control population, we found the expected association between $\mathrm{FEV}_{1} / \mathrm{FVC}$ and exposure to passive smoking, but in the VLBW population no such relationship existed. In both populations, the FVC of children exposed to smoking was greater than in those not exposed, although the effect was small and there was no evidence of a dose-response relationship when the level of smoking was taken into account.

Our data on smoking exposure were derived from parental questionnaires from cases and controls and are, therefore, subject to all the usual biases in self reporting of such behaviour. There was also a significant difference in questionnaire response between these two groups with the VLBW group responding less fre- quently ( $80 \% v 88 \%$ ). However, the lung function of the children of non-responding parents was not significantly different from those who did respond; therefore response bias does not account for our findings. Furthermore, mother's smoking behaviour recorded at the time of birth correlated highly $(88 \%)$ with data on exposure to maternal smoking at $8-9$ years. It is not possible, therefore, to clarify whether our observed smoking effect is attributable to smoking in pregnancy or current exposure or both.

We did not find a difference between the two groups in the reporting of dampness and moulds in the house, nor was there a significant relationship between their presence and measures of lung function, as has been reported previously. ${ }^{23}$ Where parents reported dampness and moulds in the home, they were also more likely to say that their child wheezed with a cold, irrespective of the study group. Wheezing in the absence of infection was increased only in the control children in association with reports of dampness and moulds. Other studies have also reported a strong and consistent relation between measures of home dampness and respiratory symptoms in children. ${ }^{24}$

Although in almost all respects, the VLBW children in this study had more respiratory problems than did their controls, these data showed that for the majority lung function was not as badly affected as we had expected. It would be informative to reassess these children's lung function in adolescence to ascertain whether there are improvements with maturation. Meanwhile these data provide a baseline for the respiratory outcomes of neonatal care for VLBW infants before the important recent advances such as the more frequent use of antenatal steroids in preterm labour and the introduction of surfactant treatment occurred.

We gratefully acknowledge the cooperation of parents and children in this study and the help of head and class teachers in facilitating the assessments. Wendy Paterson, auxologist, and Caroline King, respiratory technician, Department of Child Health, University of Glasgow, kindly helped in the training of the nurses. The Medical Research Council funded the study. The Public Health Research Unit and LM are supported by the Chief Scientist Office of the Scottish Office Home and Health Department. The opinions and conclusions expressed here are not necessarily those of that organisation.

1 Barker DP, Godfrey KM, Fall C, Osmond C, Winter PD, Shaheen SO. Relation of birth weight and childhood respiratory infection to adult lung function and death from piratory infection to adult lung function and death from 671-5.

2 Wong YC, Beardsmore CS, Silverman M. Pulmonary sequelae of neonatal respiratory distress in very low birth-
weight infants: a clinical and physiological study. Arch Dis weight infants: a clinical an

3 Myers MG, McGuinness GA, Lachenbrych PA. Respiratory illnesses in survivors of infants respiratory distress syndrome. Am Rev Respir Dis 1986; 133: 1011-8.

4 Chan KN, Noble-Jamieson CM, Elliman A, Bryan EM, Silverman $M$. Lung function in children of low birth weight. Arch Dis Child 1989; 64: 1284-93.

5 Chan KN, Noble-Jamieson CM, Elliman A, Bryan EM, Silverman M. Respiratory symptoms in children of low birth weight. Arch Dis Child 1989; 64: 1294-304.

6 McCormick MC, Shapiro S, Starfield BH. Rehospitalization in the first year of life for high risk survivors. Pediatrics 1980; 66: 991-9.

7 Hack M, De Monterice D, Merkatz IR, Jones P, Fanaraoff AA. Rehospitalization of the very low birthweight infant: a AA. Rehospitalization of the very low birthweight infant: a continuum of perinatal and en

8 Kitchen WH, Ford GW, Doyle LW, Rickards AL, Kelley EA. Health and hospital readmissions of very-low-birthweight and normal-birth-weight children. Am $\mathcal{f}$ Dis Child weight and normal-bi 
9 Mutch L, Ashurst H, Macfarlane A. Birth weight and hospital admission before the age of two years. Arch Dis Child 1992; 67: 900-4.

10 Rona RJ, Gulliford CM, Chinn S. Effects of prematurity and intrauterine growth on respiratory health and lung function in childhood. $B M F$ 1993; 306: 817-20.

11 Seidman DS, Laor A, Gale R, Stevenson DK, Danon Y. Is low birth weight a risk factor for asthma during adolescence? Arch Dis Child 1991; 66: 584-7.

12 Kitchen WH, Olinsky A, Doyle LW, et al. Respiratory health and lung function in 8 year-old children of very health and lung function in 8 year-old children of very low birth

13 Scottish Low Birthweight Study Group. The Scottish low birthweight study: I. Survival, growth, neuromotor and sensory impairment at four years. Arch Dis Child 1992; 67: 675-81.

14 Hall A, McLeod A, Counsell C, Thomson L, Mutch L. School attainment, cognitive ability and motor function in a total very low birthweight Scottish population at 8 years - a controlled study. Dev Med Child Neurol 1995; 37: 1037-50.

15 Freeman JV, Cole TJ, Chinn S. Cross sectional stature and weight reference curves for the UK, 1990. Arch Dis Child 1995; 73: 17-24.

16 Strachan DP. Repeatability of ventilatory function measure- ments in a population survey of 7 year old children. Thorax 1989; 44: 474-9.

17 Rosenthal M, Bain SH, Cramer D, et al. Lung function in white children aged 4 to 19 years: I - Spirometry. Thorax 1993; 48: 794-802.

18 Chinn S, Rona RJ. Height and age adjustment for crosssectional studies of pulmonary function in children aged 6 to 11 years. Thorax 1992; 47: 707-14.

19 Rothman KJ. Modern epidemiology. Boston: Little, Brown, 1986.

20 Agudo A, Bardagi S, Romero PV, Gonzalez CA. Exercise-induced airways narrowing and exposure to Exercise-induced airways narrowing and exposure to
environmental tobacco smoke in schoolchildren. $A m \mathscr{F}$ Epidemiol 1994; 140: 409-17.

21 Kelly YJ, Brabin BJ, Milligan P, Heaf DP, Reid J, Pearson MG. Maternal asthma, premature birth, and the risk of respiratory morbidity in schoolchildren in Merseyside. Thorax 1995; 50: 525-31.

22 Matthes JWA, Lewis PA, Davies DP, Bethel JA. Birth weight at term and lung function in adolescence: no evidence for a programmed effect. Arch Dis Child 1995; 73: 231-4.

23 Strachan DP. Damp housing and childhood asthma: validation of reporting of symptoms. BMf 1988; 297: 1223-6. 24 Brunkereef B, Dockery DW, Speizer FE, Ware JH, Spengler JD, Ferris BG. Home dampness and respiratory morbidity in children. Am Rev Respir Dis 1989; 140: 1363-7.

\section{High evolutionary theory}

Like the human lemmings who repeatedly, and apparently voluntarily, fling themselves (in caudocephalic orientation if fortune favours them) down perilous icy mountain slopes, their feet bound to slats of painted wood or some convenient modern substitute, primitive man must have been possessed of a self destructive urge. How else would you explain the fact that 25,000 years ago people took up residence high in the Himalayas, on the Tibetan plateau at 12,000 feet or more above sea level? For that, we are told, is the length of time the ancestors of present day Tibetans have been there. The vagaries of man's behaviour in the region did not, however, end there, for as we all know, some 45 years ago the Tibetans' northern neighbours decided to move in from China. And that has provided the basis of an interesting observation on darwinian natural selection (Susan Niermeyer and colleagues, New England fournal of Medicine 1995; 333: 1248-52).

Fifteen Tibetan and 15 Han Chinese normal term babies in Lhasa were studied with serial pulse oximetry over the first few months of life. The Tibetan babies had higher arterial oxygen saturations from birth. The values in both groups fell during the first week after which in the Tibetan babies mean oxygen saturation stayed at around 86 to $90 \%$ but in the Han babies it fell progressively, reaching 76 to $78 \%$ in sleep at 4 months. Almost all of the Han babies were cyanosed during sleep. It is known that some Han babies fail to thrive in Lhasa and have to be taken to low altitude and some suffer from subacute infantile mountain sickness (they develop dyspnoea and cyanosis with pulmonary hypertension and right heart failure).

The precise physiological mechanisms underlying these observations are unknown. These authors suggest that there might be a genetic difference in the response of the pulmonary vasculature to hypoxia, the Tibetan babies being more resistant to the development of pulmonary hypertension.

There must be a moral in this story, about nation's behaviour unto nation, but I struggle to put it into words without appearing to condone that most unpaediatric principle about the sins of the fathers. 